\title{
11 \\ BIOMECHANICAL CHANGES IN THE CERVICAL SPINE ALIGNMENT AFTER LUMBAR DYNAMIC STABILIZATION
}

\author{
๑ Ahmet Tulgar Bașak ${ }^{1}$, ๑ Muhammet Arif Özbek² ๑ Ali Fahir Özer ${ }^{3}$ \\ ${ }^{1}$ American Hospital, Clinic of Neurosurgery, İstanbul, Turkey \\ ${ }^{2}$ Istanbul Medipol University, Department of Neurosurgery, Istanbul, Turkey \\ ${ }^{3}$ Koç University Faculty of Medicine, Department of Neurosurgery, İstanbul, Turkey
}

\begin{abstract}
Objective: The aim of this study is to determine the biomechanical changes in cervical spine parameters following the surgical correction of lumbar deformity with dynamic stabilization, and to evaluate how the preoperative parameters are related to these changes.

Materials and Methods: Anteroposterior and lateral scoliosis radiographs of 20 patients were obtained, who underwent a dynamic stabilization (DynesysR, Zimmer, USA) and Safinaz screw peek rod placement procedures for lumbar deformity. The cervical spine parameters in the radiographs were measured in Surgimap program by an independent researcher, and they were classified into 5 categories and compared by using the Wilcoxon test in preoperative and early postoperative periods. The data were collected and analyzed using IBM SPSS Statistics $25^{\text {th }}$ Edition.

Results: Between all the parameters examined, the changes in the patients' T1 Slop Angle were found to be statistically significant ( $p$ value $<0.05$ ). Depending on this, it was concluded that dynamic stabilization of lomber deformity could change the biomechanical loads in the postoperative cervical spine alignment.

Conclusion: Dynamic stabilization surgery for spinal deformity, which is conducted to restore sagittal balance, can also lead to biomechanical improvement in the cervical spine alignment.

Keywords: Dynamic stabilization, sagittal balance, cervical spine, surgimap
\end{abstract}

\section{INTRODUCTION}

"S" shaped arrangement of the spine is the unique factor in the formation of sagittal and coronal balance. This form allows most complicated movements to be done with minimum energy consumption. It also maintains spinopelvic alignment by establishing a balance between the compensatory mechanisms of the pelvis and the head. Nowadays, these complex interactions have become more and more revealed with computer-aided measurements ${ }^{(1,2)}$.

Sagital imbalance, as seen in lumbar degenerative disease, is associated with progressive pain and disability (3). Previous studies show that surgeries for the degenerative spine, performed to correct the sagittal balance, cause significant corrective changes even outside the stabilized areas of the thoracolumbar spine ${ }^{(4)}$. These changes cause the SVA to approach to the gravity line by rearranging the axial load distribution on the cervical spine as a result of the restoration of the sagittal balance ${ }^{(5)}$.

The aim of this study is firstly to show the effect of dynamic stabilization on cervical spine alignment changes, to evaluate whether these changes influenced by a particular preoperative spine alignment, and then to determine preoperative parameters that trigger these changes on spine alignment following the corrective lumbar degenarative disease.

\section{MATERIALS AND METHODS}

\section{Patient Population}

The adult patients with consecutive lumbar degenarative diseases, who were treated with Dynesys dynamic stabilization procedure and Safinaz screw peek rod placement between 2019 and April 2021 in our hospital, were included in this study according to the surgical records. Informed consent was obtained from our patients for our study. Institutional review board approval was obtained from İstanbul Medipol University Non-Interventional Clinical Research Ethics Committee (approval number: E-10840098-772.02-5821, date: 11/11/2021). The inclusion criteria for the study were: age $>50$ years, lumbar degenerative disease status in at least 1 segment, and bilateral scoliosis on plain radiographs taken in pre- and postoperative on standart upright position. Patients diagnosed with ankylosing spondylitis, any tumor or infection, 
turkishspine

or with lumbar degenerative disease caused by neuromuscular conditions were excluded from the study. Clinical, surgical and radiographic records of the included cases were also examined.

\section{Radiological Measurements}

Full-length, standing, AP, and lateral scoliosis radiographs were obtained in a standard upright position, with arms horizontally forward and folded over the shoulder. Radiographic measurements were obtained by calibrating the Surgimap measurement program for each patient in accordance with standard techniques in scoliosis radiographs.

The angle C1-C2 (C1-2) was measured from the line between the anterior arch of $\mathrm{C} 1$ and the posterior arc of $\mathrm{C} 2$ to the line at the lower margin of body C2. The C2-C7 angle (C2-7) was measured along the line extending from the rear body of $\mathrm{C} 2$ to the rear body of C7. The slop angle T1 was measured between the upper endplate of T1 and the line along the horizontal reference line. T1-CL measurement, this was judged based on the C2-T1 Cobb angle.cSVA measurement, the distance between the plumb line through the C2 center and the plumb line of the posterior C7 upper ende plate. (Figure 1, 2, 3, 4). It has been concluded that this situation might result in biomechanical improvement in the cervical spine alignment. Scoliosis radiographs were taken just before the operation (1-2 days on average) and immediately after the surgery when the patients were mobilized (average 2-3 days).

\section{Study Design and Statistical Analysis}

Data analysis was collected and analyzed using IBM SPSS Statistics $25^{\text {th }}$ Edition. Data were irrigated after descriptive analysis. Normality analysis of the data was performed using

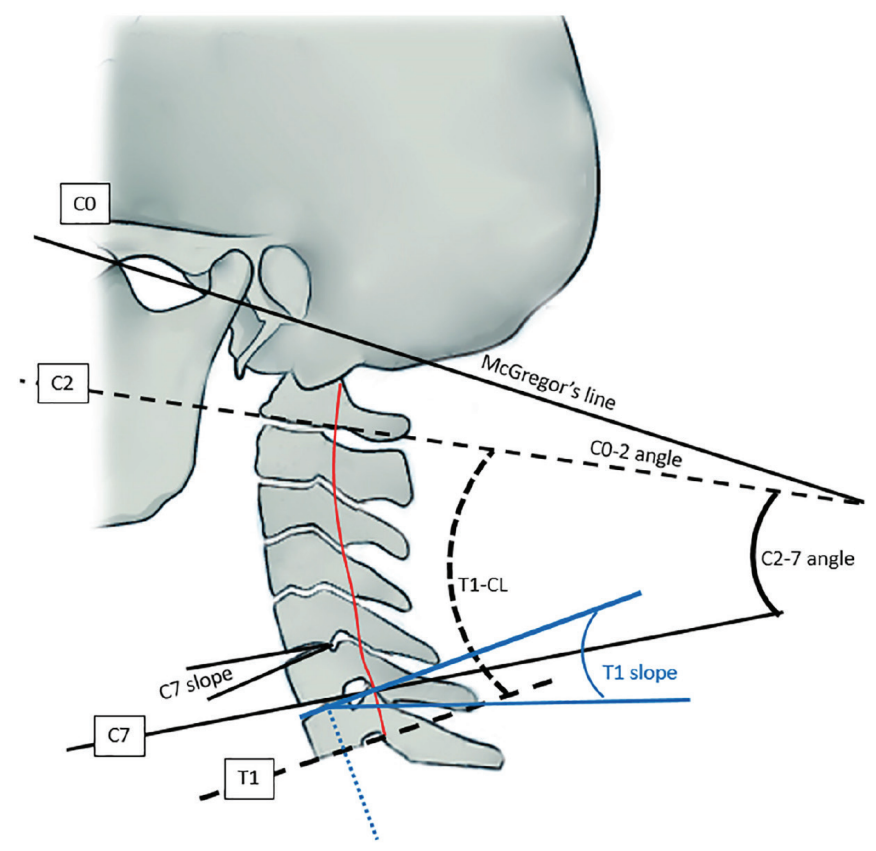

Figure 1. C0-C2 angle and C7 slop angle are shown
Kolmogorov-Smirnov test, Shapiro-Wilk test, Histogram and Variance coefficient. The dependent groups were compared using the Wilcoxon test. $P<0.05$ was considered significant.

\section{RESULTS}

The population demographics and diagnoses of 20 patients have been summarized as in Table 1 . The mean age of the patients was 65.6, and 9 male patients and 11 female patients were included in the study. Four of the patients had degenerative disc disease, 7 had spinal stenosis, 4 had previously operated spinal instability, 3 had spondylolisthesis and 2 had spondylolysis. The highest instrumental spinal cord level was L1 and the lowest instrumentation level was L5. It has been found that there is no significant difference in the demographic parameters listed in Table 1. On the other hand, there are significant changes $(p<0.05)$ found in the measurements of T1 slop angle in the parameters examined (Table 2 and 3). Then, the relationship between the T1 slop angle in single segment and long segment dynamic stabilization has statistically been analyzed and a significant difference has been found in favor of the long segment $(p<0.05)$ (Table 4) (Figure 5).

\section{DISCUSSION}

Symptomatic pain resulting from the change of normal cervical lordosis and subsequent disc herniation are known to be related to each other ${ }^{(6)}$. Therefore, understanding the compensatory behavior of the cervical spine in thoracolumbar deformity patients is of importance to prevent secondary cervical spine disorders.

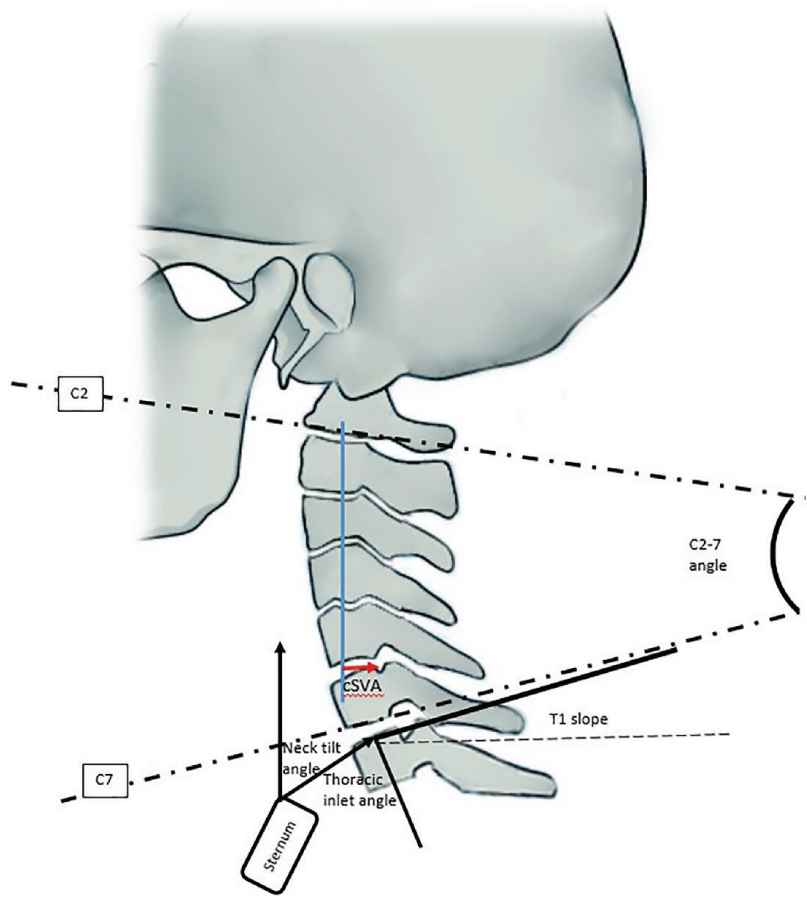

Figure 2. Thoracic inlet angle, cervical tilt angle, cSVA and C2-7 angle measurements are shown 
It is a well-known fact that a disruption in the spine alignment will affect other parts of the spine. In time, the spine has gained lordotic and kyphotic inclinations in order to economically use the distribution of the load in bipedal people, and it has gained comfortable use of both arms and hands ${ }^{(7)}$. Sagittal orientation in the spine is the position which people have in daily life

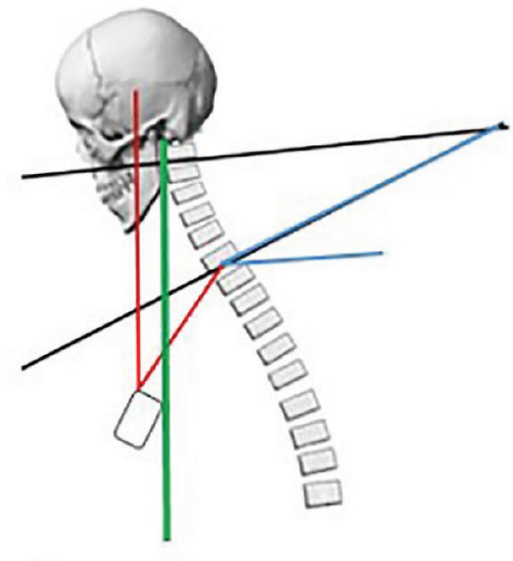

a

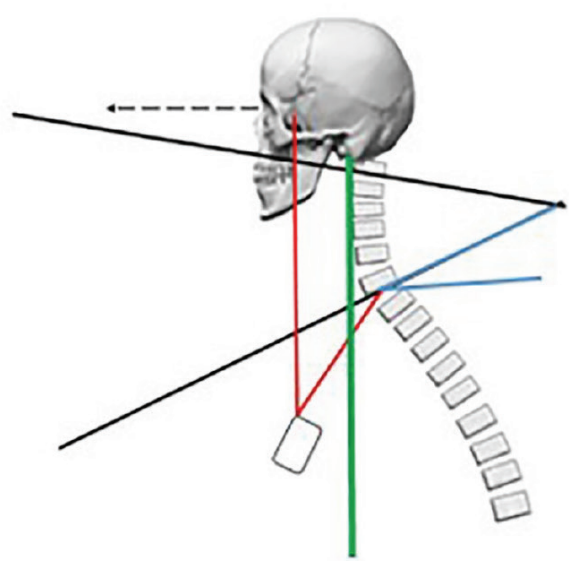

b

Figure 3. a) Relation between normal thoracic parameters and cervical region b) As thoracic kyphosis (blue) develops, T1 slop angle decreases and neck tilt increases (red)
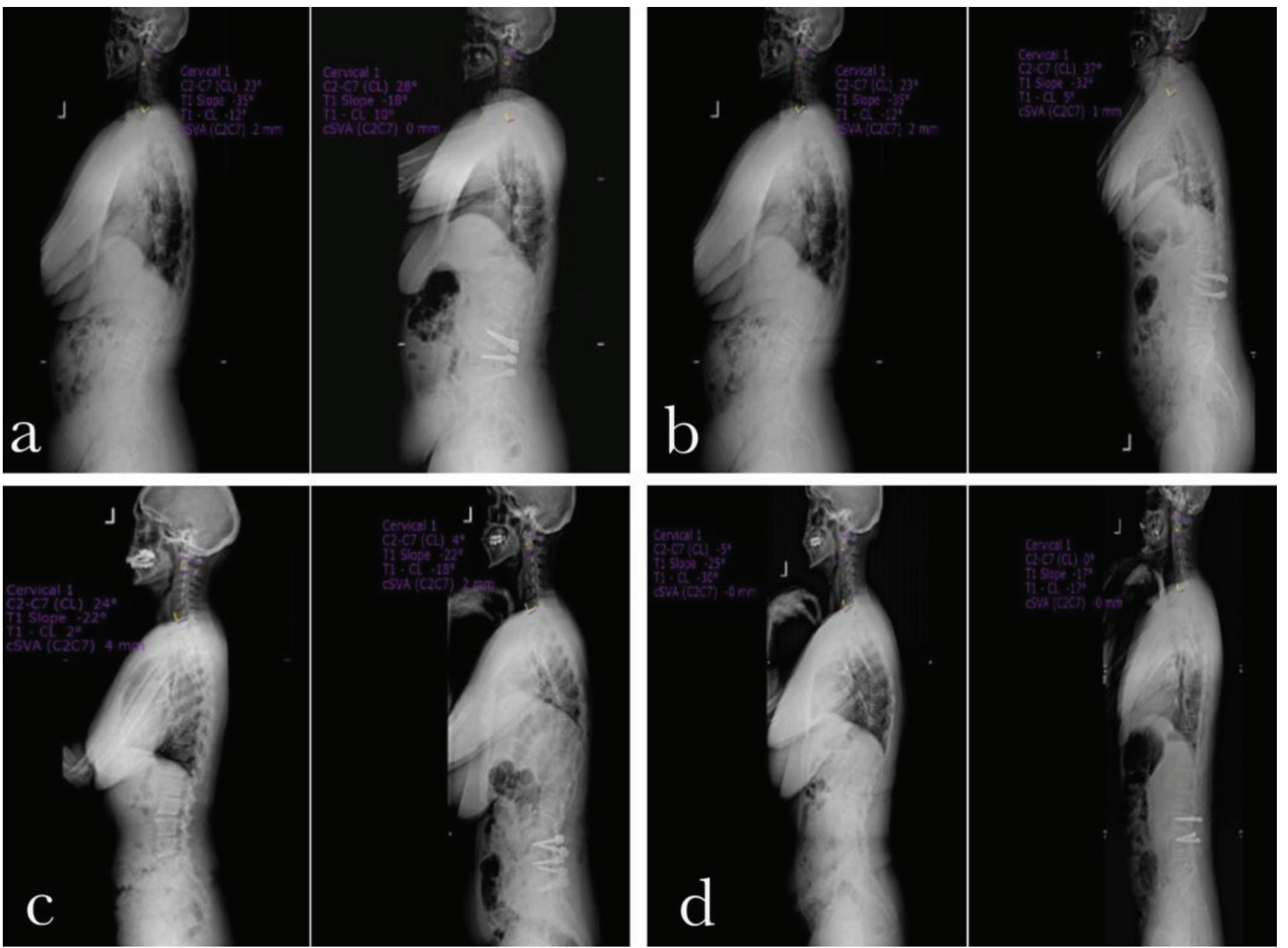

Figure 4. a. b. c. d) Preoperative and postoperative cervical biomechanic measurements 
Table 1. Demographic information and diagnosis of patients

\begin{tabular}{lllll|}
\hline Patient no & Age & Sex & Level & Diagnosis \\
\hline 1 & 61 & M & L4 & Degenerative Disc Disease \\
\hline 2 & 74 & M & L2 and L4 & Spinal Stenosis \\
\hline 3 & 58 & M & L3 & Spinal instability (Operated) \\
\hline 4 & 67 & F & L3 and L4 & Spinal Stenosis \\
\hline 5 & 60 & F & L4 & Degenerative Disc Disease \\
\hline 6 & 62 & M & L4 & Spondylolisthesis \\
\hline 7 & 66 & F & L2 & Spondylolysis \\
\hline 8 & 72 & M & L3 and L4 & Spinal Stenosis \\
\hline 9 & 75 & F & L4 & Spondylolisthesis \\
\hline 10 & 69 & M & L5 & Spinal instability (Operated) \\
\hline 11 & 56 & F & L2 & Spondylolysis \\
\hline 12 & 65 & F & L3 & Degenerative Disc Disease \\
\hline 13 & 64 & F & L4 and L5 & Spinal Stenosis \\
\hline 14 & 62 & F & L4 & Spinal instability (Operated) \\
\hline 15 & 60 & M & L4 & Degenerative Disc Disease \\
\hline 16 & 69 & $F$ & L4 and L5 & Spinal Stenosis \\
\hline 17 & 63 & M & L2 and L3 & Spinal Stenosis \\
\hline 18 & 62 & $F$ & L3 and L4 & Spinal instability (Operated) \\
\hline 19 & 76 & F & S4 & Spinal Stenosis \\
\hline 20 & 72 & M & & \\
\hline
\end{tabular}

Table 2. Examined cervical biomechanical parameters of the patients

\begin{tabular}{|c|c|c|c|c|c|c|c|c|c|c|}
\hline Patient no & $\begin{array}{l}\text { Preop } \\
\text { C1-2 }\end{array}$ & $\begin{array}{l}\text { Postop } \\
\text { C1-2 }\end{array}$ & $\begin{array}{l}\text { Preop } \\
\text { C2-7 }\end{array}$ & $\begin{array}{l}\text { Postop } \\
\text { C2-7 }\end{array}$ & $\begin{array}{l}\text { Preop } \\
\text { T1 Slope }\end{array}$ & $\begin{array}{l}\text { Postop } \\
\text { T1 Slope }\end{array}$ & $\begin{array}{l}\text { Preop } \\
\text { T1-CL }\end{array}$ & $\begin{array}{l}\text { Postop } \\
\text { T1-CL }\end{array}$ & $\begin{array}{l}\text { Preop } \\
\text { cSVA mm }\end{array}$ & $\begin{array}{l}\text { Postop cSVA } \\
\mathrm{mm}\end{array}$ \\
\hline 1 & 35 & 30 & 17 & 13 & -26 & -21 & -9 & -1 & 4 & 4 \\
\hline 2 & 25 & 29 & 12 & -8 & -24 & -8 & -12 & -21 & -3 & -2 \\
\hline 3 & 31 & 23 & 9 & 9 & -34 & -28 & -25 & -7 & -7 & -7 \\
\hline 4 & 39 & 42 & 3 & -10 & -26 & -15 & -23 & -4 & -4 & -4 \\
\hline 5 & 31 & 41 & 2 & 44 & -18 & -61 & -16 & -25 & -3 & -3 \\
\hline 6 & 25 & 35 & -21 & -2 & 0 & -4 & -21 & -6 & 1 & 4 \\
\hline 7 & 59 & 61 & -2 & 0 & -35 & -36 & -37 & -25 & -7 & -5 \\
\hline 8 & 18 & 41 & 37 & 6 & -32 & -23 & 5 & -17 & -2 & -1 \\
\hline 9 & 64 & 53 & -6 & -4 & -39 & -21 & -45 & -15 & -13 & -8 \\
\hline 10 & 27 & 31 & 19 & 13 & -33 & -16 & -14 & -3 & 3 & 1 \\
\hline 11 & 33 & 15 & 23 & 28 & -35 & -18 & -12 & 14 & 2 & 0 \\
\hline 12 & 42 & 42 & 11 & 20 & -38 & -37 & -27 & -6 & -5 & -2 \\
\hline 13 & 31 & 31 & 24 & 37 & -24 & -32 & 0 & 5 & 5 & 1 \\
\hline 14 & 35 & 47 & 30 & 10 & -25 & -27 & 5 & -15 & 5 & 1 \\
\hline 15 & 14 & 26 & 24 & 20 & -22 & -31 & 2 & -11 & 4 & 1 \\
\hline 16 & 28 & 39 & -1 & 8 & -13 & -22 & -14 & -5 & 2 & 1 \\
\hline 17 & 19 & 8 & 7 & 37 & -5 & -35 & 2 & 4 & 1 & -3 \\
\hline 18 & 38 & 28 & -5 & 4 & -25 & -22 & -30 & -2 & 0 & 2 \\
\hline 19 & 34 & 21 & 16 & 8 & -33 & -20 & -17 & -3 & -3 & -3 \\
\hline 20 & 24 & 31 & 3 & 0 & -27 & -17 & -24 & -8 & -4 & 0 \\
\hline
\end{tabular}


outside of the sleeping time. Therefore, a distortion in the lower part of the spine will naturally affect the overlapping spine posture. This situation may not necessarily be in the spine. Pathologies in the pelvis, hip joints or lower extremities also play an important role in the balance of the spine. If this unwanted interaction can be balanced by posture protection mechanisms, it may not be noticed at all, but if the compensation does not work, the balance of the spine may be disturbed ${ }^{(8,9)}$. As a result, unless there are very special conditions, a deterioration in the lumbar region affects the thoracic and cervical region and the position of the head, while thoracic region pathologies mainly affect the cervical region and the head. The position of the head is affected by a deterioration in the cervical region ${ }^{(10)}$. When the current studies have been examined, it is observed that the normal and pathological parameters of the lumbar and thoracic region are predominantly revealed and a common language is created. The parameters of the cervical region affected by indirect or direct pathologies have been studied in recent years ${ }^{(11)}$. It is understood that these parameters are similar to the projection of the lumbopelvic region. The sacral slop angle is replaced by the thoracic slop angle and the pelvic tilt by the thoracic tilt angle. The thoracic inlet angle corresponds to the pelvic incidence. The thoracic inlet angle is equal to the sum of the thoracic slop and neck tilt angle.

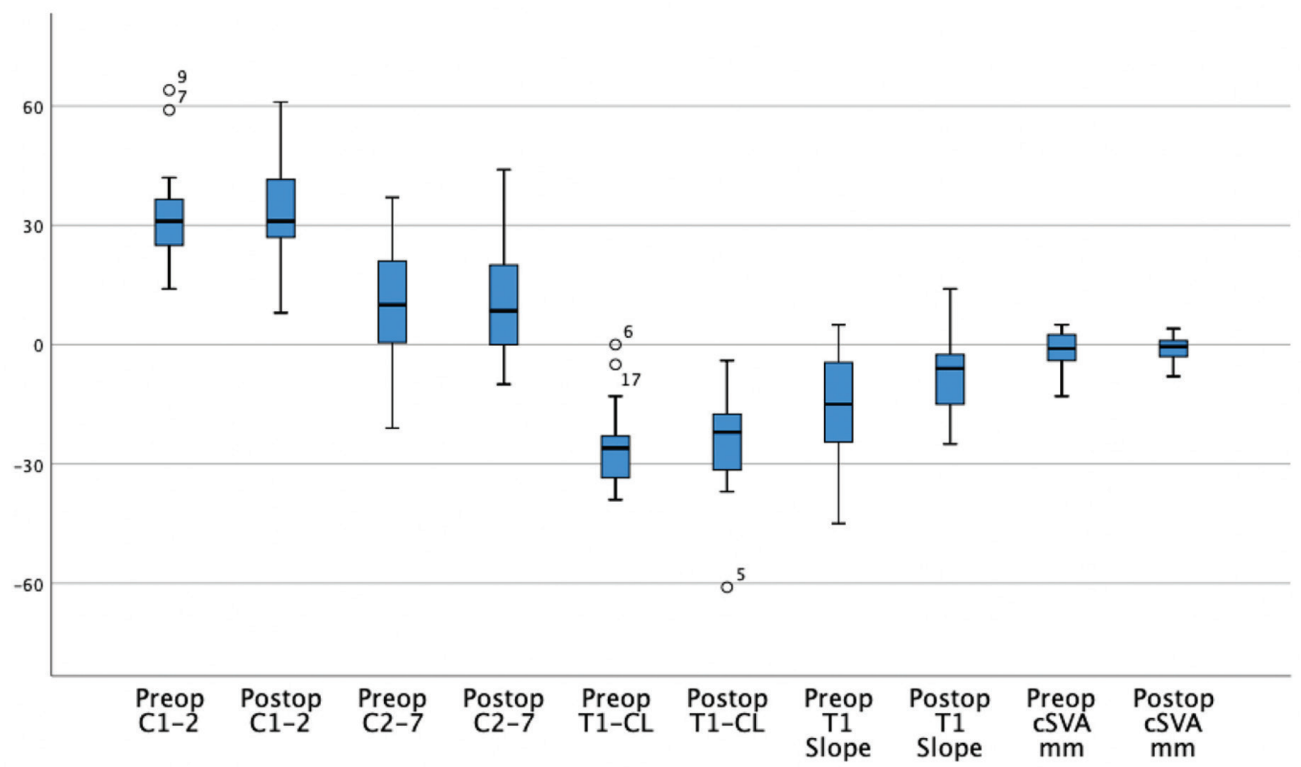

Figure 5. Statistical result cervical biomechanical parameters of patients

Table 3. Significant difference in T1 slop angle

\section{Test statistics ${ }^{\mathrm{a}}$}

\begin{tabular}{llllll}
\hline & $\begin{array}{l}\text { Postop C1-2 } \\
\text {-Preop C1-2 }\end{array}$ & $\begin{array}{l}\text { Postop C2-7 - } \\
\text { Preop C2-7 }\end{array}$ & $\begin{array}{l}\text { Postop T1 Slope - } \\
\text { Preop T1 Slope }\end{array}$ & $\begin{array}{l}\text { Postop T1-CL - } \\
\text { Preop T1-CL }\end{array}$ & $\begin{array}{l}\text { Postop cSVA mm - } \\
\text { Preop cSVA mm }\end{array}$ \\
\hline$Z$ & $-0.327^{\mathrm{b}}$ & $-0.262^{\mathrm{b}}$ & $-1,065^{\mathrm{b}}$ & $-2,017^{\mathrm{b}}$ & $-0.029^{\mathrm{b}}$ \\
\hline Asymp. Sig. (2-tailed) & 0.744 & 0.793 & 0.287 & 0.044 & 0.977 \\
\hline $\begin{array}{l}\text { a: Wilcoxon-signed ranks test } \\
\text { b: Based on negative ranks }\end{array}$ & & & & & \\
\hline
\end{tabular}

Table 4. Significant difference in T1 slop angle between the single segment and multi segment lumbac dynamic stabilization patients

\section{Pairwise Comparisons \\ Measure: Preop Postop T1-CL}

\begin{tabular}{|c|c|c|c|c|c|c|}
\hline \multirow[b]{2}{*}{ (I) Grup } & \multirow[b]{2}{*}{ (J) Grup } & \multirow[b]{2}{*}{ Mean difference (I-J) } & \multirow[b]{2}{*}{ Standard error } & \multirow[b]{2}{*}{ Signature ${ }^{b}$} & \multicolumn{2}{|c|}{$95 \%$ confidence interval for difference ${ }^{b}$} \\
\hline & & & & & Lower bound & Upper bound \\
\hline 1 segment & $>1$ segment & $-9,250^{*}$ & 3,808 & 0,026 & $-17,251$ & $-1,249$ \\
\hline
\end{tabular}

Based on estimated marginal means

*: The mean difference is significant at the

b: Adjustment for multiple comparisons: Bonferroni 
Especially these parameters are very important in evaluating lumbar and thoracic pathologies together with those in the cervical regions ${ }^{(12,13)}$.

It is known that thoracic and cervical regions are very affected by the lumbar fixed sagittal balance deformity. This situation suggests that postoperative cervical spine alignment may depend on changes in regional lumbar anatomic curvature and sagittal alignment, and the observed cervical changes differ depending on the preoperative sagittal alignment. There is a similar case in the state of imbalance that occurs after instrumentation surgery in which lumbar lordosis is not preserved. In cases where the movement at the bottom is destroyed, the upward effect becomes clear. However, it has not yet been investigated whether or how much the cervical region is affected in dynamic systems in which the functional segment is stabilized mobile in the spine. When the posture is deteriorated, the response in the upper cervical region is the increasing response of the $\mathrm{CO}-\mathrm{C} 2$ angle, but there is no significant difference in the cases in this study. Here, it can be concluded that the deterioration in posture is not enough to affect this area.

In this study, the reciprocal changes of cervical spine alignment following the dynamic lumbar stabilization surgery have been identified and it has been induced by preoperative parameters. It has been found that there is no change in lumbar dynamic stabilization, cervical slop angle in cervical parameters, thoracic inlet and cervical tilt angles, except for mutual interaction in individuals without sagittal balance problems, in other subaxial parameters. While the cervical tilt and thoracic inlet angle increase naturally, the cervical slop angle also decreases. As the dynamic stabilization level increases, these values vary in parallel. It is possible to say that this is an effort of the head to look in the horizontal plane in order to increase the cervical tilt.

\section{CONCLUSION}

In this study, it has been concluded that it is very important to preserve lumbar lordosis in the dynamically stabilized spine, even if it is segmental. Although it starts to slightly and it does not affect the daily life in the early periods, it may be the first step of serious problems in the following years. In addition, it is remarkable that the cervicothoracic region is the region that responds the earliest in maintaining the neck posture.

\section{Ethics}

Ethics Committee Approval: Institutional review board approval was obtained from İstanbul Medipol University NonInterventional Clinical Research Ethics Committee (approval number: E-10840098-772.02-5821, date: 11/11/2021).
Informed Consent: Informed consent was obtained from patients.

Peer-review: Internally peer-reviewed.

\section{Authorship Contributions}

Surgical and Medical Practices: A.T.B., A.F.Ö., Concept: A.T.B., A.F.Ö., Design: A.T.B., M.A.Ö., Data Collection or Processing: A.T.B., A.F.Ö., Analysis or Interpretation: M.A.Ö., Literature Search: A.F.Ö., Writing: A.T.B.

Financial Disclosure: The authors declared that this study received no financial support.

Conflict of Interest: The authors have no conflicts of interest to declare.

\section{REFERENCES}

1. Boulay C, Tardieu C, Hecquet I, Benaim C, Mouilleseaux B, Marty $C$, et al. Sagittal alignment of spine and pelvis regulated by pelvic incidence: standard values and prediction of lordosis. Eur Spine J. 2006; 15:415-22.

2. Hilibrand AS, Tannenbaum DA, Graziano GP, Loder RT, Hensinger RN The sagittal alignment of the cervical spine in adolescent idiopathic scoliosis. J Pediatr Orthop. 1995; 15:627-32.

3. Glassman SD, Bridwell K, Dimar JR, Horton W, Berven S, Schwab F The impact of positive sagittal balance in adult spinal deformity. Spine (Phila Pa 1976). 2005;30:2024-29.

4. Klineberg E, Schwab F, Ames C, Hostin R, Bess S, Smith JS, et al. Acute reciprocal changes distant from the site of spinal osteotomies affect global postoperative alignment. Adv Orthop. 2011;2011:415946.

5. Ha Y, Schwab F, Lafage V, Mundis G, Shaffrey C, Smith J, et al Reciprocal changes in cervical spine alignment after corrective thoracolumbar deformity surgery. Eur Spine J. 2014;23:552-59.

6. Miyazaki M, Hymanson HJ, Morishita $Y$, He W, Zhang H, Wu G, et al. Kinematic analysis of the relationship between sagittal alignment and disc degeneration in the cervical spine. Spine (Phila Pa 1976). 2008;33:E870-E76.

7. Niemitz C. The evolution of the upright posture and gait-a review and a new synthesis. Naturwissenscahaften. 2010;97:241-63.

8. Ozer AF, Kaner T, Bozdogan C. Sagittal Balance in the Spine. Turkish Neurosurgery. 2014;24:13-19.

9. Roussouly P, Gollogly S, Berthonnaud E, Labelle H, Weidenbaum $M$. Sagittal alignment of the spine and pelvis in the presence of L5-S1 isthmic lysis and low-grade spondylolisthesis. Spine. 2006;31:2484-90.

10. Özer AF, Ateş Ö, Çerezci Ö, Hekimoğlu M, Aydın AL, Öktenoğlu T, et al. Changes in cervical sagittal alignment and the effects on cervical parameters in patients with cervical spondylotic myelopathy after laminoplasty. J Craniovertebr Junction. 2021;12:183-90.

11. Özer AF. Servikal Balans. Chapter 4. In: Özer AF(ed) Servikal Omurga Cerrahisi. US Akademi, Izmir. 2021; pp. 31-7.

12. Hann S, Chalouhi N, Madineni R, Vaccaro AR, Albert TJ, Harrop J, et al. An algorithmic strategy for selecting a surgical approach in cervical deformity correction. Neurosurg Focus. 2014;36:E5.

13. Roussouly P, Pinheiro- Franco JL. Sagittal parameters of the spine: biomechanical approach. Eur Spine J. 2011;20:578-85. 